\title{
PENTINGNYA ANALISIS SWOT UNTUK MENINGKATKAN KINERJA SDM (Studi Kasus Usaha Mikro Kecil dan Menengah Malang)
}

\author{
Rahayu Puji Suci' ${ }^{1)}$, Adya Hermawati ${ }^{2)}$ Suwarta $^{3)}$ \\ Email : ${ }^{1)}$ poppedot87@gmail.com, ${ }^{2)}$ wati_wati38@yahoo.co.id, ${ }^{3)}$ suwarta78@ymail.com \\ 1,2) Magister Manajemen Program Pasca Sarjana Universitas Widyagama Malang \\ ${ }^{3}$ ) Agribisnis Fakultas Pertanian Universitas Widyagama Malang
}

\begin{abstract}
Abstrak
Perlunya evaluasi strategi dalam menghadapi pasar yang dinamis dapat mendukung suatu organisasi untuk mampu berkompetisi, bahkan mampu memenangkan persaingan. Namun UMKM walaupun memiliki fleksibilitas dan ketahanan yang tinggi dalam perekonomian, beberapa keterbatasan seperti kapabilitas finansial dan sumber daya manusia membuat UMKM harus dapat menentukan strategi yang tepat dalam meraih keunggulan kompetitif. Tujuan dari penelitian ini adalah menentukan strategi pengembangan kinerja sumber daya manusia pada UMKM di Kota Malang melalu implementasti analisis SWOT (Strengths, Weakneses, Opportunities, dan Threatments). Hasil menunjukkan indikator Strength yang paling tinggi adalah S5 (Pelayanan) yaitu sebesar 4.20. Sementara itu, indikator Weakness yang paling tinggi adalah W4 (Kualitas Sumber Daya Manusia), yaitu sebesar 3.20. Kemudian indikator Opportunity yang paling tinggi adalah O1 (Oleh-oleh khas daerah) dan O5 (Bahan Baku) yaitu sebesar 4. Sementara itu, indikator Threat yang paling tinggi adalah T3 (Pesaing pendatang baru), yaitu sebesar 2.3. Kemudian untuk lokasi titik potong A, B, C, dan D, yaitu titik E, berada kuadran I (Strategi agresif). Dengan demikian, analisis SWOT terhadap UMKM di Kota Malang menunjukkan posisi yang bagus, sehingga dapat diterapkan strategi SO.
\end{abstract}

Kata kunci: SWOT, UMKM, strategi peningkatan kinerja.

\begin{abstract}
The need for evaluation of strategies in dealing with dynamic markets can support an organization to be able to compete, even able to win the competition. However, although UMKM has high flexibility and resilience in the economy, several limitations such as financial capabilities and human resources make MSMEs must be able to determine the right strategy in achieving competitive advantage. The purpose of this study is to determine the strategy for developing human resource performance at MSMEs in Malang through the implementation of SWOT analysis (Strengths, Weaknesses, Opportunities, and Treatments). The results show the highest Strength indicator is S5 (Service), which is equal to 4.20. Meanwhile, the most top Weakness indicator is W4 (Quality of Human Resources), which is 3.20. Then the highest Opportunity indicator is O1 (ByProducts typical) and O5 (Raw Materials) that is equal to 4. Meanwhile, the most top Threat indicator is T3 (Competing new entrants), which is 2.3. Then for the intersection points $A, B$, $C$, and $D$, which are point $E$, are in quadrant I (aggressive strategy). Thus, SWOT analysis of MSMEs in Malang shows a good position, so that SO strategies can be applied.
\end{abstract}

Keywords: SWOT, SMEs, performance improvement strategies

\section{PENDAHULUAN}

Lingkungan bisnis saat ini dihadapkan pada dinamika pasar yang sangat kompetitif. Untuk itu, organisasi perlu menghadapinya dengan kemampuan beradaptasi dan agility sehingga mampu mencapai keunggulan kompetitif yang berkelanjutan. Bisnis UMKM di Malang Raya adalah salah satu potensi ekonomi kerakyatan yang sedang dikembangkan oleh Dinas Koperasi dan UMKM di Kota Malang. Hal ini dimaksudkan untuk meningkatkan kesejahteraan masyarakat dengan memberdayakan UMKM. Empat tahap perkembangan UMKM yaitu tahap start-up, growth, expansion, dan going overseas perkembangan UMKM (Suci, 2009; Purnamasari, Suci and Handini, 2013; Suci, 2013; Suci and Priyono, 2013). Untuk Indonesia tahapan ini belum sepenuhnya berjalan dengan baik dikarenakan berbagai 
hambatan seperti kondisi finansial, sumber modal, teknlogi dan sumber daya manusia (Hadjimanolis, 1999; Erdil and Erbiyık, 2015).

Selain itu, pemerintah Indonesia belum memiliki the role of thumb dari model pembinaan UMKM yang terintegrasi untuk mencapai kinerja yang diharapkan. Dalam artikel ini, teridentifikasi aspek sumber daya manusia merupakan kunci keberhasilan UMKM (Purnamasari, Suci and Handini, 2013; Suci, 2013; Suci and Priyono, 2013).

Tujuan dari artikel ini adalah untuk mengetahui sampai sejauh mana kekuatan, kelemahan, peluang, dan ancaman pengembangan UMKM di kota Malang, sehingga dapat menjadi titik awal untuk menentukan strategi yang sesuai bagi UMKM kota Malang. Maka pada artikel ini, strategi pengembangan SDM diinvestigasi dan dianalisa sehingga dapat dilakukan pemetaan posisi strategis UMKM berdasarkan análisis SWOT. Ringkasan Analisis Faktor Eksternal Strategis (EFAS) dan Ringkasan Analisis Faktor Strategis Internal (IFAS) dipertimbangkan dalam membangun matriks SWOT (Suci and Priyono, 2013)

\section{METODE}

\section{Jenis Penelitian, Lokasi Penelitian, dan Sumber Data}

Penelitian ini menggunakan jenis penelitian kualitatif dengan pendekatan deskriptif yaitu sebuah penelitian yang bertujuan membuat pencandraan secara sistematis, faktual dan akurat mengenai fakta-fakta dan sifat-sifat obyek penelitian. Lokasi penelitian dilakukan di kota Malang yang berfokus pada Usaha Mikro Kecil dan Menengah.

Data yang digunakan pada penelitian ini adalah data primer dan data sekunder. Data primer merupakan data yang diperoleh dari pengamatan langsung di lapangan dan data yang diperoleh dari hasil wawancara dan pengisian kuesioner oleh responden pilihan. Hal yang harus dipastikan adalah responden tersebut merupakan pihak yang memahami tentang perkembangan kondisi SDM Usaha Mikro Kecil dan Menengah di Kota Malang. Data sekunder merupakan data pendukung dari data primer yang diperoleh dari studi literature, penelitian terdahulu, dan bahan pustaka lain yan relevan.

\section{Metode Analisis}

Analisis SWOT merupakan metode analisis yang membandingkan faktor internal, yaitu kekuatan (stregth), dan kelemahan (weakness) dengan faktor eksternal yaitu peluang (opportunity), dan ancaman (threats). Faktor internal dimasukan kedalam matrik yang disebut matrik faktor IFAS (Internal Strategic Faktor Analisis Summary). Faktor eksternal dimasukan kedalam matrik yang disebut matrik faktor eksternal atau EFAS (Eksternal Strategic Faktor Analisis Summary). SWOT dapat menjadi alat yang digdaya dan mampu mengeksplorasi kemungkinan-kemungkinan perencanaan strategi baru maupun memulai program yang baru (Chermack and Kasshanna, 2007). Chermack and Kasshanna (2007) menguraikan tahapan SWOT yang terangkum dalam gambar 1 .

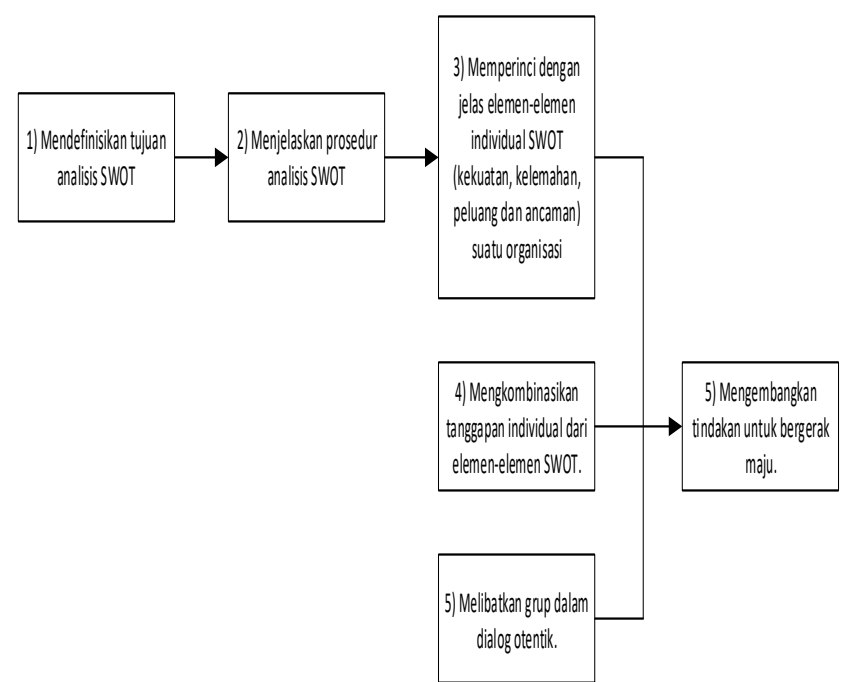

Gambar 1. Tahapan SWOT

Diadopsi dari Chermack and Kasshanna (2007).

Langkah Satu: Tentukan Tujuannya

Langkah pertama dalam SWOT adalah menentukan tujuan eksplisit yang telah disetujui oleh semua peserta tim penganalis dalam proses perencanaan strategi. Pendefinisian ini harus dilakukan dengan hati-hati. Hal ini karena jika terjadi kegagalan dalam identifikasi tujuan maka perencanaan sumber daya dapat menjadi tidak efisien dan sia-sia.

Langkah Dua: Jelaskan Prosesnya kepada Peserta Tim Penganalis

Setelah tujuan telah ditetapkan dan disetujui, langkah kedua yaitu menjelaskan pada peserta Tim Penganalis tentang prosedur analisis SWOT. Pada tahap ini, perencanaan kegiatan di masa depan harus diklarifikasi dan dijadwalkan dengan jelas dan disetujui oleh semua partisipan.

Langkah Tiga: Memperoleh Kontribusi Individu

Langkah ketiga menampilkan aspek-aspek analisis SWOT dengan meminta para peserta mengisi matriks kekuatan, kelemahan, peluang, dan ancaman yang saat ini dihadapi organisasi.

Langkah Empat: Merangkum Kontribusi semua peserta

Setelah kontribusi individu telah diperoleh, selanjutnya mengumpulkan tanggapan-tanggapan tersebut menjadi satu gambaran besar yang berisi semua perspektif tentang kekuatan, kelemahan, peluang, dan ancaman organisasi.

Langkah Kelima: Memfasilitasi Dialog Strategis

Memfasilitasi dialog strategis dapat menjadi bagian yang paling potensial dalam analisis SWOT dalam menciptakan perubahan berdasarkan sudut pandang peserta Tim Penganalis. Sangat penting untuk mengidentifikasi kekuatan yang bisa dipandang sebagai kelemahan dan peluang yang bisa jadi mengandung ancaman tersembunyi. Selain itu, dialog strategis dapat merencanakan berbagai tindakan yang disesuaikan tujuan yang ingin dicapai atau keadaan akhir yang ingin dicapai. Karena dari SWOT, organisasi dapat memanfaatkan kekuatan, mengatasi kelemahan, mengambil keuntungan penuh dari peluang, dan meminimalkan dampak ancaman, maka SWOT dapat mengidentifikasi masalah 
yang dianggap kunci bagi kinerja organisasi saat ini dan di masa yang akan datang

\section{HASIL DAN PEMBAHASAN}

\section{Analisis SWOT}

Pada tahap ini dilakukan penyebaran kuesioner ke UMKM, kemudian dihitung nilai rata-rata dari setiap item. Selanjutnya dengan data berupa rata-rata dari 20 UMKM, dilakukan analisis SWOT. Hasil penilaian terhadap faktor internal UMKM Kota Malang disajikan dalam bentuk Gambar 2, sementara hasil penilaian terhadap faktor eksternal UMKM Kota Malang disajikan dalam bentuk Gambar 3.
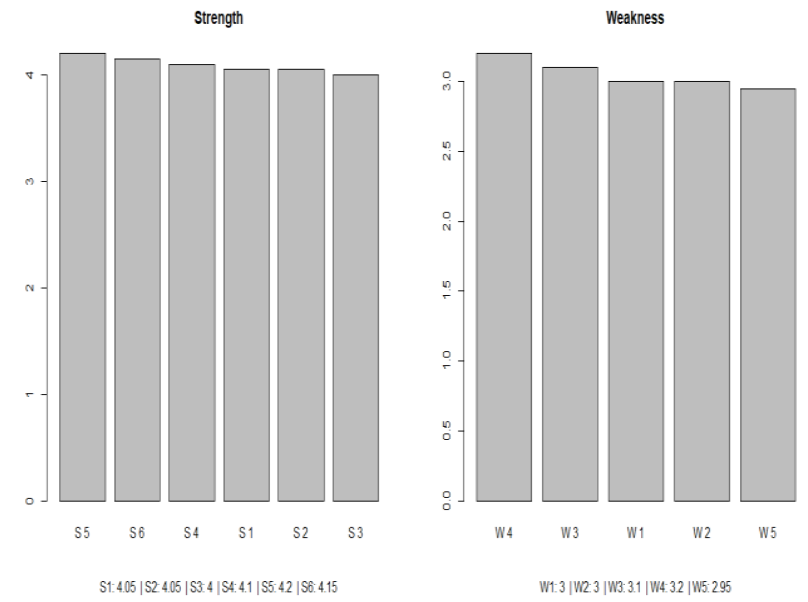

Gambar 2. Faktor Internal Kota Malang

Keterangan:

S1: Kualitas produk

S2: Brand image

S3: Harga

S4: Lokasi

S5: Pelayanan

S6: Pelanggan tetap

W1: Overproduksi

W2: Ruang lingkup distribusi

W3: Kegiatan promosi

W4: Kualitas SDM

W5: Kekurangan modal untuk pengembangan bisnis

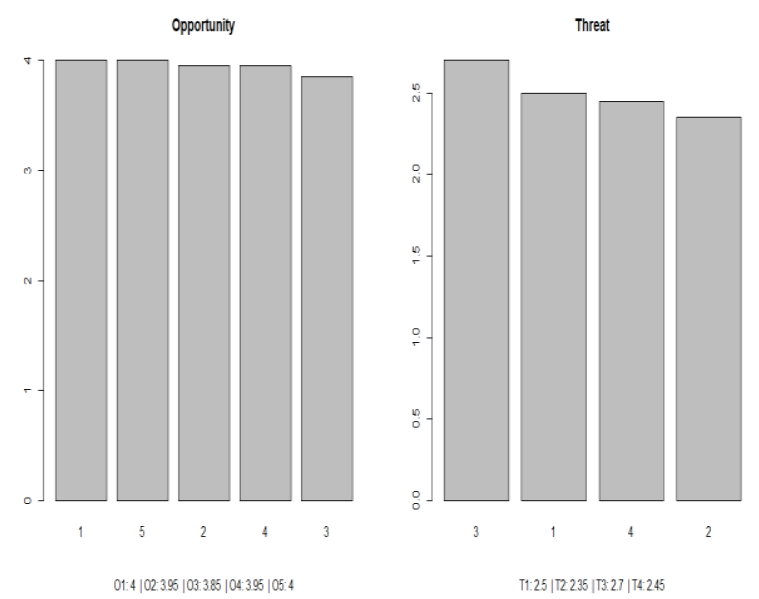

Gambar 3. Faktor Eksternal Kota Malang
Keterangan:

O1: Oleh-oleh khas daerah

O2: Pangsa pasar

O3: Hubungan baik dengan sesama pengusaha

O4: Kemajuan teknologi

O5: Bahan baku

T1: Pergeseran konsumsi masyarakat

T2: Ruang lingkup distribusi pesaing

T3: Pesaing pendatang baru

T4: Harga pesaing

Berdasarkan Gambar 2, indikator Strength yang paling tinggi adalah S5 (Pelayanan) yaitu sebesar 4.20. Hal ini dapat diartikan bahwa Pelayanan yang ditawarkan UMKM di Kota Malang sudah sesuai dengan ekspektasi pelanggan. Sementara itu, indikator Weakness yang paling tinggi adalah W4 (Kualitas Sumber Daya Manusia), yaitu sebesar 3.20. Hal ini dapat diartikan bahwa permasalahan kurangnya skill dan pengetahuan SDM merupakan masalah internal yang perlu diperhatikan oleh UMKM di Kota Malang.

Berdasarkan Gambar 3, indikator Opportunity yang paling tinggi adalah $\mathrm{O} 1$ (Oleh-oleh khas daerah) dan $\mathrm{O} 5$ (Bahan Baku) yaitu sebesar 4. Hal ini dapat diartikan bahwa oleh-oleh khas daerah sangat diminati pelanggan serta bahan baku yang dibutuhkan UMKM di Kota Malang melimpah. Sementara itu, indikator Threat yang paling tinggi adalah T3 (Pesaing pendatang baru), yaitu sebesar 2.3. Hal ini dapat diartikan bahwa pesaing pendatang baru cukup mengancam UMKM yang sudah ada lebih dulu di Kota Malang.

Total skor faktor internal dan eksternal UMKM di Kota Malang disajikan dalam Tabel 1.

Tabel 1

\section{Total Skor Faktor Internal dan Eskternal} Kota Malang

\begin{tabular}{|l|c|c|c|}
\hline Internal & Skor & Eksternal & Skor \\
\hline Strengh & 4.0917 & Opportunity & 3.9591 \\
\hline Weakness & -3.0312 & Threat & -2.5150 \\
\hline Total & 1.0604 & Total & 1.4441 \\
\hline
\end{tabular}

Berdasarkan Tabel 1 diperoleh bahwa skor Strength lebih besar daripada skor Weakness sehingga diperoleh total skor dengan tanda positif. Selain itu, skor Opportunity lebih besar daripada skor Threat sehingga diperoleh total skor dengan tanda positif. Setelah diperoleh skor, maka dapat dibuat plot SWOT dengan titik A, B, C, dan D seperti pada Gambar 4.

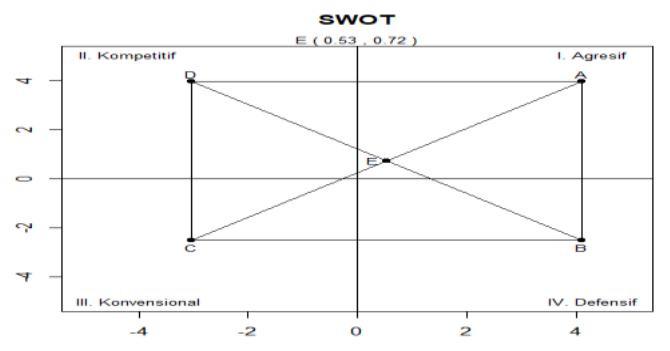

Gambar 4. Plot SWOT Kota Malang 
Untuk menentukan strategi dapat dilihat melalui lokasi titik potong $\mathrm{A}, \mathrm{B}, \mathrm{C}$, dan D, yaitu titik E. Berdasarkan Gambar 4, titik E berada kuadran I. Dapat disimpulkan bahwa kuadran yang paling luas adalah kuadran I. Dengan demikian, analisis SWOT terhadap UMKM di Kota Malang menunjukkan posisi yang bagus, sehingga dapat diterapkan strategi SO.

Cara lain untuk menentukan strategi adalah dengan menghitung luas setiap kuadran yang dibatasi oleh titik A, B, C, dan D. Selanjutnya dipilih kuadran yang paling luas sebagai strategi. Hasil perhitungan luas pada analisis SWOT di Kota Malang dimuat dalam Tabel 2 berikut ini.

Tabel 2

Luas Wilayah Kuadran Kota Malang

\begin{tabular}{|c|c|c|}
\hline Kuadran & Luas & Rank \\
\hline I & 16.19945 & 1 \\
\hline II & 12.00082 & 2 \\
\hline III & 7.623468 & 4 \\
\hline IV & 10.29063 & 3 \\
\hline
\end{tabular}

\section{PENUTUP}

\section{Simpulan}

Berdasarkan pada hasil dan pembahasan yang telah diuraikan sebelumnya, maka dapat disimpulkan bahwa:

1. Indikator Strength yang paling tinggi adalah S5 (Pelayanan). Hal ini dapat diartikan bahwa Pelayanan yang ditawarkan UMKM di Kota Malang sudah sesuai dengan ekspektasi pelanggan.

2. Sementara itu, indikator Weakness yang paling tinggi adalah W4 (Kualitas Sumber Daya Manusia). Hal ini dapat diartikan bahwa permasalahan kurangnya skill dan pengetahuan SDM merupakan masalah internal yang perlu diperhatikan oleh UMKM di Kota Malang.

3. Kemudian indikator Opportunity yang paling tinggi adalah O1 (Oleh-oleh khas daerah) dan O5 (Bahan Baku). Hal ini dapat diartikan bahwa oleh-oleh khas daerah sangat diminati pelanggan serta bahan baku yang dibutuhkan UMKM di Kota Malang melimpah.

4. Sementara itu, indikator Threat yang paling tinggi adalah T3 (Pesaing pendatang baru). Hal ini dapat diartikan bahwa pesaing pendatang baru cukup mengancam UMKM yang sudah ada lebih dulu di Kota Malang.

5. Kemudian untuk Titik $\mathrm{E}$ yang merupakan perpotongan titik A, B, C, dan D berada kuadran I (Strategi agresif). Dengan demikian, analisis SWOT terhadap UMKM di Kota Malang menunjukkan posisi yang bagus, sehingga dapat diterapkan strategi SO.

\section{Saran}

Keterbatasan pada riset ini adalah analisis yang hanya dilakukan pada satu kota yang mungkin akan berbeda hasilnya jika diterapkan pada kota yang lain di Jawa Timur maupun di Indonesia. Sehingga hasil penelitian ini masih belum bisa menggeneralisasi kota lainnya. Selanjutnya perlu penelitian lebih lanjut untuk implementasi pada kota lainnya sebagai agenda penelitian di masa yang akan datang. Penelitian selanjutnya juga dapat menggabungkan analisis SWOT dan metode analisis keputusan seperti AHP dan ANP, sehingga perumusan strategi terbaik untuk UMKM dapat teridentifikasi.

\section{DAFTAR PUSTAKA}

Chermack, T.J. and Kasshanna, B.K., 2007. The use and misuse of swot analysis and implications for hrd professionals. Human Resource Development International. 10(4), 383-399.

Erdil, A. and Erbıyık, H., 2015. Selection Strategy via Analytic Hierarchy Process: An Application for a Small Enterprise in Milk Sector. In: World Conference on Technology, Innovation and Entrepreneurship Selection. 2618-2628.

Hadjimanolis, A., 1999. Barriers to innovation for SMEs in a small less developed country (Cyprus). Technovation, 19(9), 561-570.

Suci, R.P., 2009. Peningkatan Kinerja Melalui Orientasi Kewirausahaan, Kemampuan Manajemen, dan Strategi Bisnis (Studi pada Industri Kecil Menengah Bordir di Jawa Timur). Jurnal Manajemen dan Kewirausahaan. 11, 46-58.

Suci, R.P., 2013. Analysis Strategy for Small and Medium Business Development Policy Gresik District in East Java. IOSR Journal of Business and Management. 8(1), 1-9.

Suci, R.P. and Priyono, 2013. Analysis Of Small Industries Development Strategy Craft " Cindogo " ( Case Study Center Industry In The Small Village Crafts Cindogo District Tapen Bondowoso). Developing Country Studies. 3(11), 19-30. 